\title{
A Result Analysis of Control Scheme for a Stand-Alone Wind Energy Conversion System
}

\author{
Nikita Choudhary $^{1}$, Prashant Garg ${ }^{2}$ \\ M. Tech Scholar, Electrical and Electronic Engineering, Scope College of Eng., Bhopal, India ${ }^{1}$ \\ Assistant Professor, Electrical and Electronic Engineering, Scope College of Eng., Bhopal, India ${ }^{2}$
}

\begin{abstract}
In this paper proposed result analysis of control scheme for a stand-alone wind energy conversion system. Wind energy conversion system (WECS) is nowadays deployed for meeting both grid-connected and stand-alone load demands. However, wind flow by nature is intermittent. In order to ensure continuous supply of power suitable storage technology is used as backup. In this paper, the sustainability of a 4-kW hybrid of wind and battery system is investigated for meeting the requirements of a $3-\mathrm{kW}$ stand-alone dc load representing a base telecom station. Present energy want greatly depends on the quality sources. But the inadequate accessibility and steady increase inside the value of typical sources has shifted the main focus toward renewable sources of energy.
\end{abstract}

Keywords: Maximum power point tracking (MPPT), pitch control, state of charge (SoC), wind energy conversion system (WECS).

\section{INTRODUCTION}

This Energy is the measured to be the essential input for Because of the event of technology within the development. At the present due to the depletion of synchronous and asynchronous generators, it's potential to obtainable standard resources and anxiety relating to effectively use these generators in WECS.

environmental deprivation, the renewable sources are being used to fulfil the ever rising energy needed. Because of a comparatively low value of electricity production wind energy is considered to be one in all the potential sources of fresh energy for the longer term. However the character of wind flow is random. Thus rigorous testing is to be accepted get into laboratory to extend economical management strategy for wind energy conversion system (WECS). The wind energy is used for complete load or connected to grid. ENERGY is taken into account to be the essential input for development. At this time because of the reduction of accessible standard resources and concern concerning environmental degradation, the renewable sources are being used to fulfil up the ever increasing energy demand. Because of a comparatively low price of electricity production wind energy is taken into account to be one in all the potential sources of fresh energy for the longer term; however the character of wind flow is schocastic. Wind energy is one in all the quickest growing sources of electricity these days. The Wind energy, the world's quickest growing energy supply, could be a clean and renewable supply of energy that has been in use for hundreds of years in Europe and additional recently within the u. s. and different nations. Wind turbines, each massive and little, manufacture electricity for utilities and residential house owners and remote villages. Wind Energy Conversion System (WECS) is one in all the foremost versatile non-conventional resources of energy because of the ever-growing demand of electricity provide. Since wind could be a natural supply and its utility relies on the climatically variation, it's essential to faucet this energy effectively for meeting the demand.

\section{THEORY}

The principle aim of control within the turbine systems operation is to convert wind energy to mechanical energy that successively is used to provide electricity. These systems are characterized by nonlinear aerodynamic behavior and depend upon a stochastic uncontrollable wind force as a driving signal. To conceptualize the system from analysis and control styles to real application, AN accurate overall mathematical model of the turbine dynamics is needed.

Normally, the model is obtained by combining the constituent scheme models that along compose the turbine dynamics. In recent years, wind energy conversion systems are deployed in large numbers in electricity grids throughout the world. Their impact on the operation of power systems could be a growing area of analysis. This thesis presents a control methodology for turbine systems that are interfaced to the grid through power-electronic converters. It's shown that fast power fluctuations excited within the conversion system by the wind may be contained instead of transferred to the grid. Also, the utilization of the turbine hub's energy storage capability for filtering slow power fluctuations is explored. It's shown that a stability limit exists on the maximum filtering cut-off frequency, which this limit may be guardedly estimated. Application of the management methodology ends up in a simplified model of the wind energy conversion system as a first-order filter of the incoming wind generation. 


\section{METHOD}

\section{A. Control scheme}

We have the following two control schemes.

- Pitch control Scheme.

- MPPT (P\&O) Scheme.

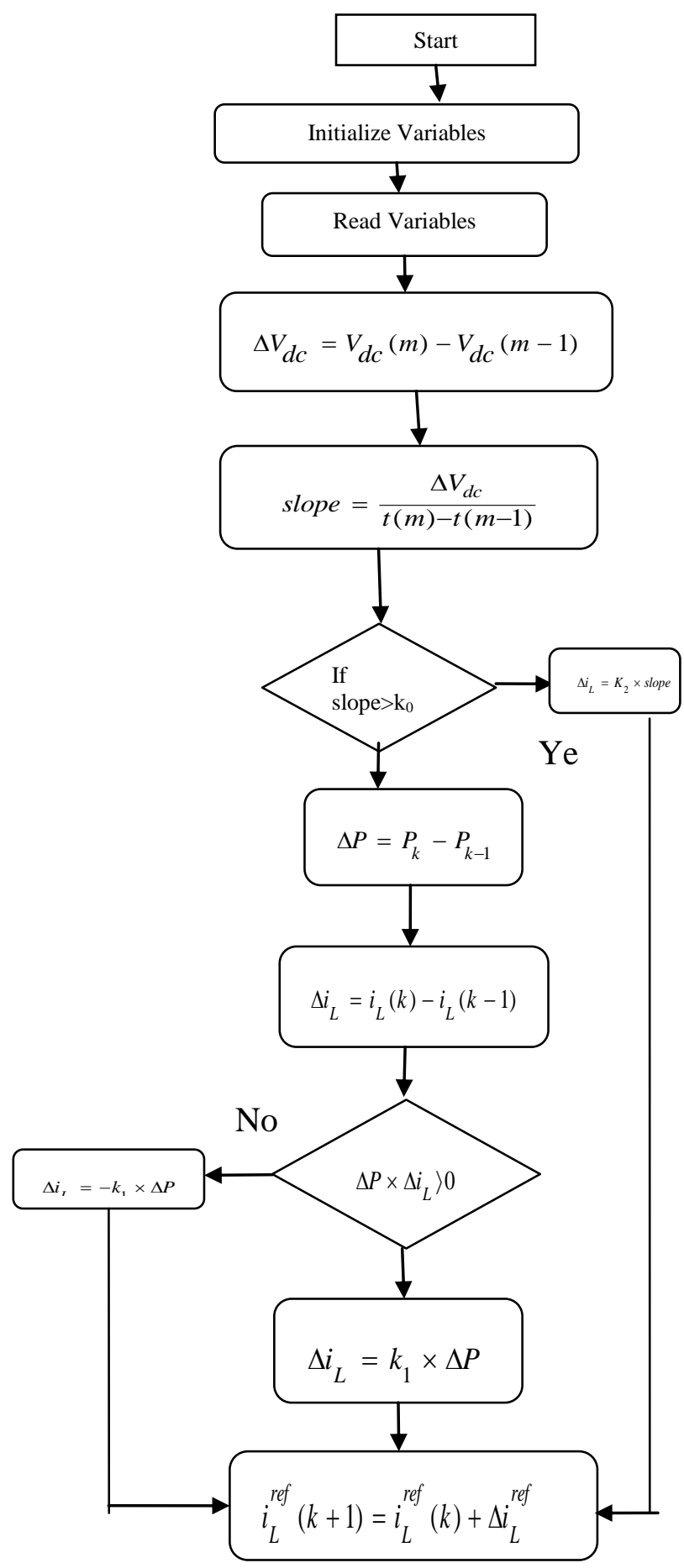

Fig. 1 Flow chart of the MPPT Algorithm

B. Working of Pitch Control Scheme

In the pitch control scheme p.u value of each input is compared with one to compute the error. The errors are tuned by PI controller. The max block selects the highest output from each PI controller which is then passed on to a limiter to create the pitch command for the WT. The actual pitch command is to be matched with the limited value. The lower limit of the pitch command is set at zero. It arises an error when the actual pitch command goes above or below the particular limit. This is to be multiplied with the error found from each of the comparator. The product is compared with zero to obtain the switch logic for integrator saturation. The pitch controller changes the pitch command attributable to variation in turbine rotation speed, power and output voltage of rectifier, that make sure safe operation of the WECS.

\section{Working of MPPT}

The MPPT algorithm proposed to track the MPP by perpetually adjusting the inductor current to reach the MPP. The dc-link voltage is not controlled. Thus, it will be monitored and the natural comportment of the dc voltage during wind speed change will be acclimating to enhance the tracking speed of the algorithm. The algorithm works in two distinct modes: The normal P\&O mode under slow wind fluctuation conditions in which an adaptive step size is employed with the power increment utilized as a scaling variable. The second mode is the predictive mode under sudden wind speed change conditions; this mode is responsible for bringing the operating point to the vicinity of the MPP during expeditious wind speed change, and it will avail obviate the generator from stalling by rapidly adjusting the generator torque in replication to sudden drops in wind speed. In this mode, the dc-link voltage slope is utilized as a scaling variable and is utilized to determine the next perturbation direction. Proposed MPPT algorithm will run as mundane adaptive step size P\&O algorithm unless a wind speed change causes the system to rapidly expedite or decelerate. In this case, the system will counteract the expedition/deceleration by transmuting the reference current felicitously and moving the operating point much more proximate to the incipient MPP. Then, the algorithm will then resume normal $\mathrm{P} \& \mathrm{O}$ mode. This method results in a saliently conspicuous tracking speed enhancement. More importantly, the system is averted from sudden stalling during sudden wind speed reductions.

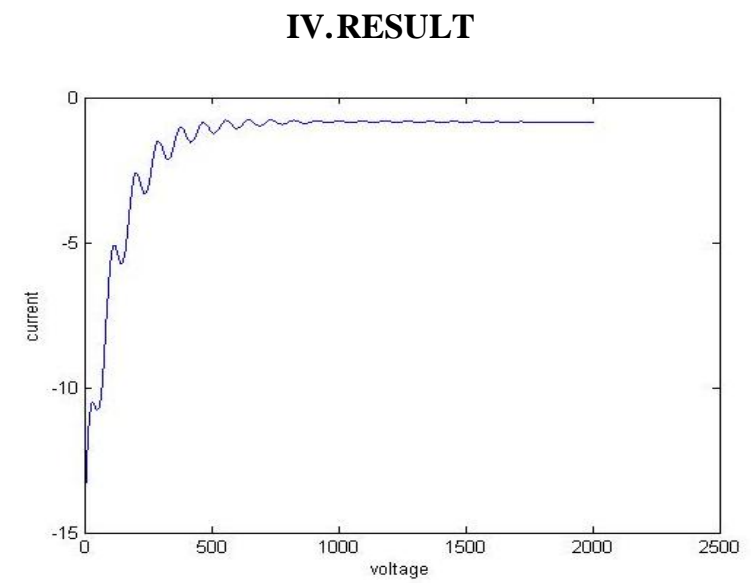

Fig.2: current vs voltage graph. 
Vol. 4, Issue 1, January 2017

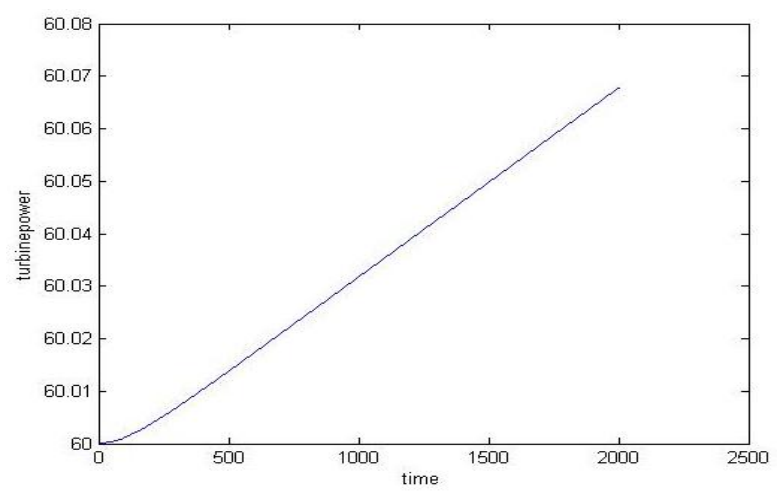

Fig.3: turbine power vs time graph

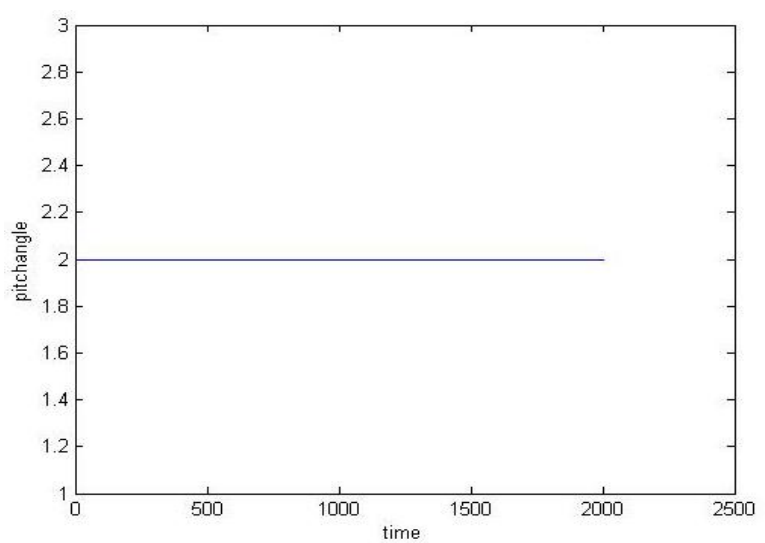

Fig.4: Pitch angle vs time.

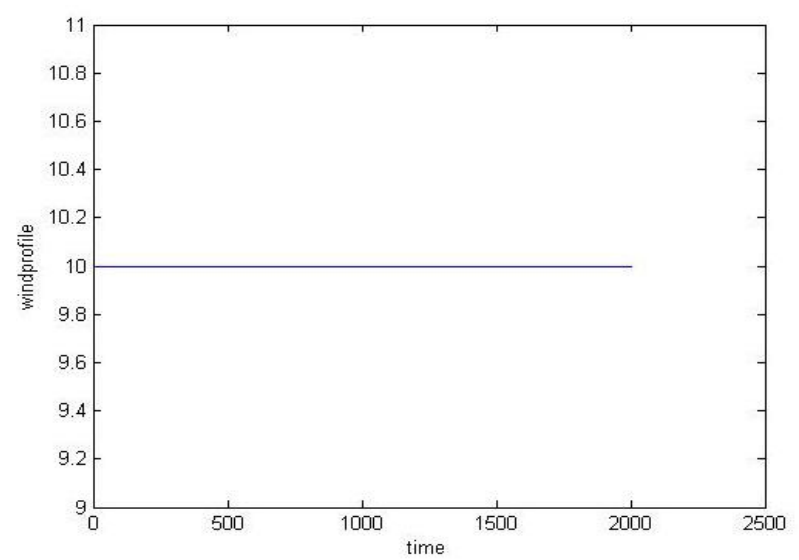

Fig.5: wind profile vs time.

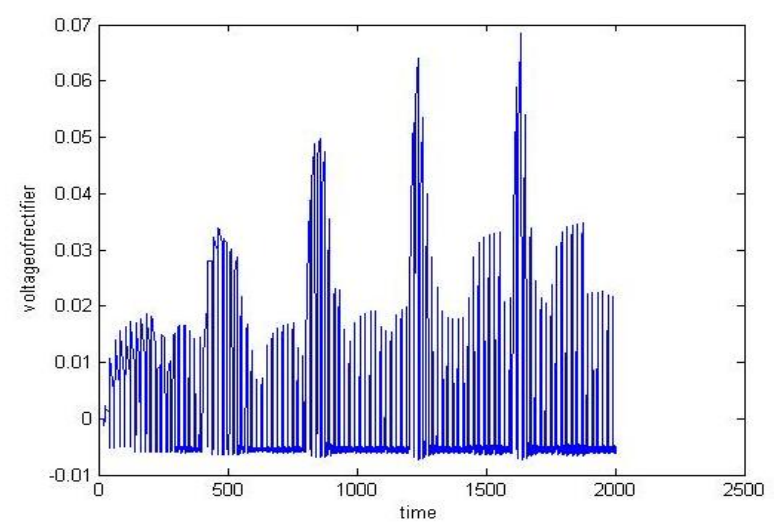

Fig. 6: Rectifier vol vs time graph.

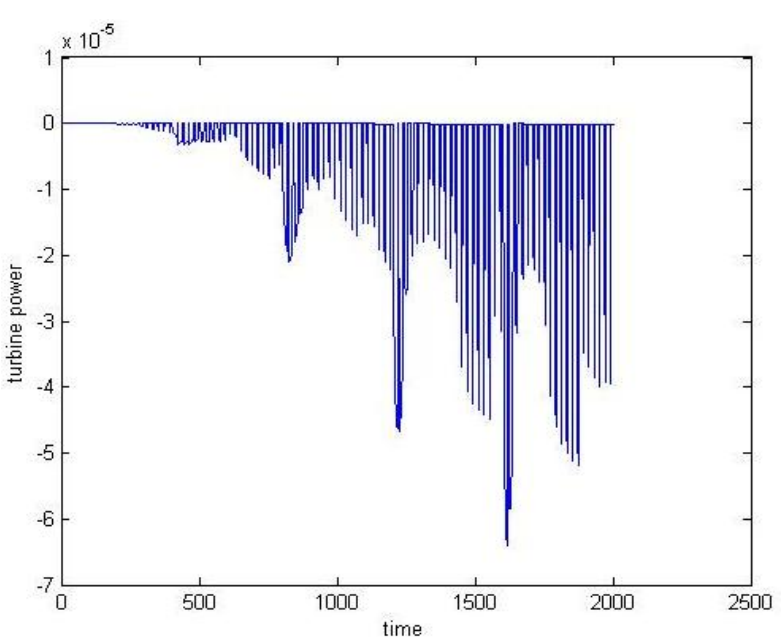

Fig.6: Turbine power vs time graph.

\section{CONCLUSION}

Wind energy that could be a kind of renewable energy, has the potential to be used for power generation. Power generated by wind energy isn't simply comparatively easier however is additionally far more environmental friendly compared to power generation exploitation nonrenewable sources just like the fossil fuels and coals. Wind energy conversion system (WECS) is currently deployed for meeting both grid-connected and stand-alone load demands. In this proposed model reduces the cost and gives maximum efficiency. Wind power has unique ability to provide even greater source of distributed energy production. This model will give maximum output with minimum source of utilization.

\section{REFERENCES}

[1] S. Aradhya Sambhu Satpathy, N. K. Kishore, Debaprasad Kastha, Mem and N. C. Sahoo, "Control Scheme for a Stand-Alone Wind Energy Conversion System", IEEE TRANSACTIONS ON ENERGY CONVERSION, VOL. 29, NO. 2, JUNE 2014

[2] Mohammad Taghi Ameli, Saeid Moslehpour, Amin Mirzaie, "Feasibility Study for Replacing Asynchronous Generators with Synchronous Generators in Wind Farm Power Stations", Proceedings of The 2008 IAJC-IJME International Conference.

[3] R. Saidur , M.R. Islam, N.A. Rahim, K.H. Solangi, "A review on global wind energy policy", Renewable and Sustainable Energy Reviews 14 (2010) Elsevier.

[4] Francisco Díaz-Gonzáleza, Andreas Sumpera,Oriol GomisBellmunta,Roberto Villafáfila-Roblesb, "A review of energy storage technologies for wind power applications", Renewable and Sustainable Energy Reviews 16 (2012) Elsevier.

[5] M. Narayana, G. A. Putrus, M. Jovanovic, P. S. Leung and S. McDonald, "Generic Maximum Power Point Tracking Controller for Small Scale Wind Turbines", Renewable Energy 2012

[6] Saket Bihari, Preeti Gupta, "Control Scheme for a StandAloneWind Energy Conversion System -A Review", International Journal of advancement in electronics and computer engineering ( IJAECE) Volume 4, Issue 9, Jan. 2016.

[7] G. K. Singh, "Self excited generator research-A survey," Electric Power Syst. Res., vol. 69, no. 2/3, pp. 107-114, 2004.

[8] S. C. Tripathy, M. Kalantar, and N. D. Rao, "Wind turbine driven self excited induction generator," Energy Convers.Manag., vol. 34, no. 8, pp. 641-648, 1993.

[9] A. Chakraborty, "Advancements in power electronics and drives in interface with growing renewable energy resources," Renewable Sustainable Energy Rev., vol. 15, no. 4, pp. 1816-1827,May 2011. 
[10] F. D. Gonz'alez, A. Sumper, O. G. Bellmunt, and R. V. Robles, "A review of energy storage technologies for wind power applications," Renewable Sustainable Energy Rev., vol. 16, no. 4, pp. 2154-2171,May 2012.

[11] N. S. Hasan, M. Y. Hassan, M. S. Majid, and H. A. Rahman, "Review of storage schemes forwind energy systems," Renewable Sustainable Energy Rev., vol. 21, pp. 237-247,May 2013.

[12] A. M. D. Broe, S. Drouilhet, and V. Gevorgian, "A peak power tracker for small wind turbines in battery charging applications," IEEE Trans. Energy Convers., vol. 14, no. 4, pp. 1630-1635, Dec. 1999.

[13] R. Kot, M. Rolak, and M. Malinowski, "Comparison of maximum peak power tracking algorithms for a small wind turbine," Math. Comput. Simul., vol. 91, pp. 29-40, 2013.

[14] M. Narayana, G. A. Putrus, M. Jovanovic, P. S. Leung, and S. McDonald, "Generic maximum power point tracking controller for small-scale wind turbines," Renewable Energy, vol. 44, pp. 72-79, Aug. 2012.

[15] K. Y. Lo, Y. M. Chen, and Y. R. Chang, "MPPT battery charger for standalone wind power system," IEEE Trans. Power Electron., vol. 26, no. 6, pp. 1631-1638, Jun. 2011. 